\title{
Risk Ratio Differences in the Exposure to Caesarean Section in the Central Area of the Western Highlands of Yemen
}

\author{
Amat Al-Khaleq O. Mehrass ${ }^{1, ~}$, Abdulelah H. Al-Adhroey ${ }^{2}$, Abdullatif D. Ali ${ }^{3}$ \\ ${ }^{1}$ Department of Gynaecology and Obstetrics, Faculty of Medicine and Health Sciences, Thamar University, Dhamar, Yemen \\ ${ }^{2}$ Division of Applied Medicine, Faculty of Medicine and Health Sciences, Thamar University, Dhamar, Yemen \\ ${ }^{3}$ Department of Biochemistry, Faculty of Medicine and Health Sciences, Thamar University, Dhamar, Yemen \\ Email address: \\ amatmehrass@gmail.com (A. Al-Khaleq O. Mehrass), husssien75@gmail.com (A. H. Al-Adhroey), abdullatifwhite@gmail.com (A. D. Ali) \\ ${ }^{*}$ Corresponding author
}

To cite this article:

Amat Al-Khaleq O. Mehrass, Abdulelah H. Al-Adhroey, Abdullatif D. Ali. Risk Ratio Differences in the Exposure to Caesarean Section in the Central Area of the Western Highlands of Yemen. American Journal of Health Research. Vol. 4, No. 4, 2016, pp. 86-90.

doi: 10.11648/j.ajhr.20160404.13

Received: June 6, 2016; Accepted: June 16, 2016; Published: June 29, 2016

\begin{abstract}
Compared to vaginal deliveries, caesarean section (C-section) is a major surgery that could be associated with higher risks of maternal and infant mortality and morbidity. In Yemen, some recent reports indicated overuses of C-section. This was a cross-sectional study aimed to assess the risk ratio difference in $\mathrm{C}$-section exposure between Yemeni mothers according to their demographic variables. A total of 400 participants of reproductive age visiting health centers for obstetric care in the central area of the western highlands of Yemen were randomly interviewed using a pretested questionnaire. The results found that the prevalence of $\mathrm{C}$-section exposure among the study participants was $22 \%$. Mothers' demographic variables showed significant differences in the risk ratio of $\mathrm{C}$-section exposure. Among these variables, large differences in the risk ratio of $\mathrm{C}$-section exposure were estimated between urban versus rural $(\mathrm{RR}=3.9, \mathrm{ER}=2.9, P<0.001)$ and literate versus illiterate mothers $(\mathrm{RR}=3.8, \mathrm{ER}=2.8, P<0.001)$. Relatively moderate differences were revealed by parity and maternal age variables $(\mathrm{RR}=2.7 ; \mathrm{ER}=1.7 ; P<0.001, \mathrm{RR}=2.6 ; \mathrm{ER}=1.6 ; P<0.001$, respectively). Age at marriage, employment status, and visiting health services practice, however, were associated with low differences in the $\mathrm{C}$-section exposure. To strengthen the mother and infant health programs in Yemen, maternal variables including place of residence and educational status should be considered as predictors for either an unnecessary or additionally needed C-section.
\end{abstract}

Keywords: Caesarean Section, Demographic Variables, Risk Ratio, Maternal and Infant Health, Obstetric Care, Yemen

\section{Introduction}

Although the cesarean section (C-section) delivery is introduced to protect maternal and infant lives, this major surgery is associated with higher risks of maternal and neonatal mortality and morbidity compared to vaginal delivery [1-2]. Recently, C-section shows an excess use throughout the world causing further health problems and economic burden to people and health providers [3-4]. On the other hand, the underuse of $\mathrm{C}$-section is found to be associated with higher levels of mortality among mothers and infants in poor countries lacking an adequate basic health care. [5-6].
Regarding the ideal rate for $\mathrm{C}$-section, the international healthcare community started that "There is no justification for any region to have a rate higher than 10-15\%" [7]. However, the World Health Organization (WHO) worldwide ecologic study shows that the association of $\mathrm{C}$-section rate and mortality is justified by socioeconomic factors [8]. The study indicated that mortality of the mother and her neonate decreased when a below $10 \% \mathrm{C}$-section rates increased, whereas an above $10 \%$ to $30 \%$ rates have no effect on mortality. Accordingly, about 69 around the world have $\mathrm{C}$-section rates ranging from $17 \%$ to $50 \%$ [9]. Among the Arab World, the highest rates of C-section of 23\% and 28\% are reported among Lebanese and Egyptians, respectively 
[10-11]. Data from neighboring countries such as Bahrain, Qatar and Oman revealed an adequate use of 16\% [12-13].

In Yemen, the available literature suggests that the incidence of C-section had considerably increased over the last decade, from $1.4 \%$ in 1997 to $30 \%$ since 2013 [14-15]. In a poor country like Yemen, the negative consequences of excess $\mathrm{C}$-section on maternal and infant health and economy of the family and community should be considered. Therefore, the present study was aimed to assess some maternal variables as potential predictors for increasing the exposure to $\mathrm{C}$-section among Yemeni women residing the Central Area of the Western Highlands.

\section{Methodology}

\subsection{Study Area and Study Population}

The study was carried out in Dhamar district, the central area of the western highlands region of Yemen. It is about 2400 meters over sea level and located 100 kilometers south of Sana'a city. The study participants were randomly selected from the governmental health services providing an obstetric care, namely; Al-Gadad Health Centre, Al-Wehdh Health Centre, Al-Homeat Hospital, Dhamar General Hospital, Maternal and Child Health Centre and Yemen Red Crescent Center. Four hundred (400) married women aged 15 - 49 years voluntary participated in this survey.

\subsection{Study Design}

This case-control study was conducted during the period from June 2013 to March 2014. The study design was planned with a $95 \%$ confidence level and 0.50 expected frequency.

The study data were collected using pretested questionnaire. The following demographic variables were available during this survey: maternal age, place of residence, educational and employment statuses, age at marriage, parity, and visiting health services practice for obstetric care. To assess the risk ratio differences between the study groups, exposure to $\mathrm{C}$-section was investigated as the dependent variable and the demographic variables as the explanatory variables. The prevalence of $\mathrm{C}$-section exposure is determined by dividing the number of participants who had one or more previous exposures to $\mathrm{C}$-section by the total number of the study participants.

This study was approved by the TU Medical Ethical Committee (TUMEC) at the Faculty. A verbal consent was obtained from each woman and their participation was completely voluntary.

\subsection{Data Analysis}

Data were statistically analyzed using IBM SPSS software (version 22.0). Differences in the exposure of the participants to $\mathrm{C}$-section were dichotomously presented as a percentage (\%) according to their demographic variables. For instance, maternal age $(\leq 24$ years $=0,>24$ years $=1)$; place of residence (urban $=0$, rural $=1)$; educational status $(\mathrm{R} \& \mathrm{~W}=0$, Illiterate $=1)$; employment status (employed $=0$, unemployed
$=1)$; age at marriage $(\leq 19$ years $=0,>19$ years $=1)$; parity (primip $=0$, multi-to-grand $=1$ ); and visiting health services (limited $=0$, regular $=1)$. Risk ratio $(\mathrm{RR})$ difference in the exposure to $\mathrm{C}$-section between the women groups was evaluated using chi-square test. The estimated risk ratio $(\mathrm{ER}=$ $R R-1)$ for predicting $C$-section exposure among the study population was then developed. $\mathrm{P}$ value of $\leq 0.05$ was used as the level of significance.

\section{Results}

\subsection{General Characteristic of the Participants}

Four hundreds (400) married women aged between 15 and 49 years participated in this survey. More than of one-third $(36.8 \%)$ of the participants were between 15 and 24 years old. Fifty-seven percent $(57 \%)$ were urban residents. Regarding educational and employment status, most of women had the ability to read and write (R\&W) a simple letter and unemployed (69\% and 77\%, respectively). Almost half (47\%) of them had married at or below age 19 . However, only $17 \%$ had given one live birth compared to the majority (83\%) who had two or more. Similarly, $17 \%$ of the participants reported that they had a limited practice of visiting health services for obstetric care while the majority had a regular visiting practice.

\subsection{Prevalence of Cesarean Section Exposure}

As shown in Figure 1, twenty two percent (22\%: 87/400) of the study participants had exposed to C-section deliveries. However, the majority (78\%: 313/400) of mothers, never exposed to the $\mathrm{C}$-section, had reported vaginal deliveries (normal $=75 \%$ and assisted $=3 \%$ ).

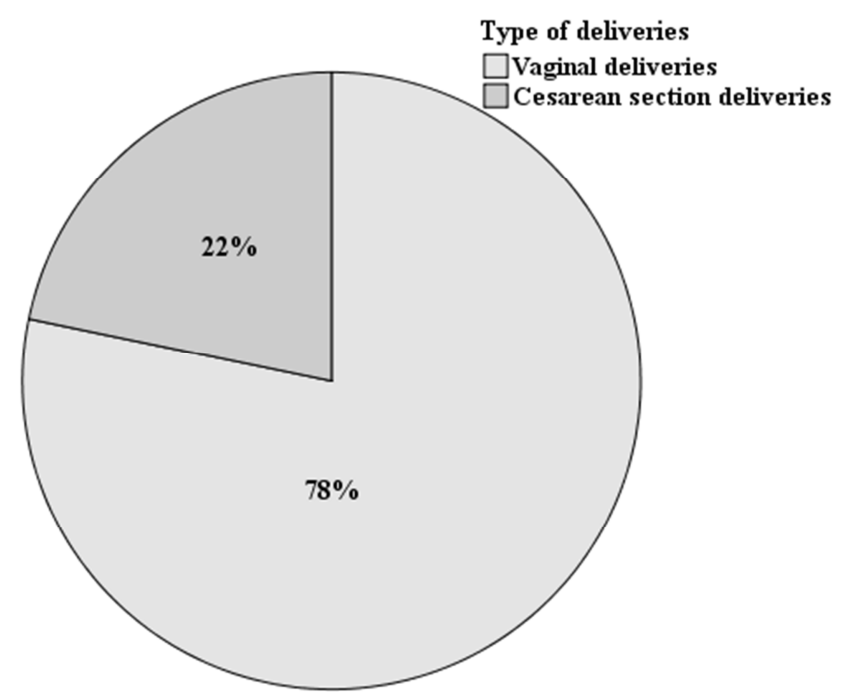

Figure 1. Prevalence of caesarean section in the central area of western highlands of Yemen

\subsection{Distribution of Cesarean Section}

The distribution of C-section exposure by the demographic variables of the study participants is shown in Table 1 . As 
parallel with the vaginal deliveries, the distribution of $\mathrm{C}$-section prevalence differed considerably by the maternal demographic variables. Women aged $\leq 24$ years showed a higher exposure than those aged $>24$ years $(35.4 \%$ compared to $13.8 \%$, respectively). Similar results were also reported by urban-rural residence $(32.0 \%$ vs. $8.1 \%)$, R\&W-illiterate educational status $(27.6 \% \quad$ vs. $7.3 \%) \quad$ and employed-unemployed position $(30.5 \%$ vs. $17.0 \%)$. Accordingly, the study participants showed higher rates of C-section exposure by their $\leq 19$ age marriage $(27.8 \%$ vs. $14.9 \%$ ) and primip parity (45.6\% vs.16.9\%). Mothers with a limited practice of visiting health center for obstetric care showed higher rate of $\mathrm{C}$-section exposure than those who had indicated a regular practice $(32.8 \%$ vs. $19.5 \%)$.

Table 1. Distribution of cesarean section exposure among the study participants $(N o=400)$.

\begin{tabular}{|c|c|c|}
\hline \multirow{2}{*}{ Demographic variables } & \multicolumn{2}{|l|}{ C-section exposure } \\
\hline & Had exposed* N (\%) & Never exposed $* *$ N (\%) \\
\hline \multicolumn{3}{|l|}{ Maternal age } \\
\hline$\leq 24$ years & $52(35.4)$ & $95(64.6)$ \\
\hline$>24$ years & $35(13.8)$ & $218(86.2)$ \\
\hline \multicolumn{3}{|l|}{ Place of residence } \\
\hline Urban & $73(32.0)$ & $155(68.0)$ \\
\hline Rural & $14(8.1)$ & $158(91.9)$ \\
\hline \multicolumn{3}{|l|}{ Educational status } \\
\hline $\mathrm{R} \& W$ & $75(27.6)$ & $197(72.4)$ \\
\hline Illiterate & $9(7.3)$ & $11592.7)$ \\
\hline \multicolumn{3}{|l|}{ Employment status } \\
\hline Employed & $43(30.5)$ & $98(69.5)$ \\
\hline Unemployed & $44(17.0)$ & $215(83.0)$ \\
\hline \multicolumn{3}{|l|}{ Age at marriage } \\
\hline$\leq 19$ years & $59(27.8)$ & $153(72.2)$ \\
\hline$>19$ years & $28(14.9)$ & $160(85.1)$ \\
\hline \multicolumn{3}{|l|}{ Parity } \\
\hline Primip & $31(44.9)$ & $38(55.1)$ \\
\hline Multi-to-grand & $56(16.9)$ & $275(83.1)$ \\
\hline \multicolumn{3}{|l|}{ Visiting health services } \\
\hline Limited & $22(32.8)$ & $45(67.2)$ \\
\hline Regular & $65(19.5)$ & $268(80.5)$ \\
\hline
\end{tabular}

* Mothers had exposed one or more times to C-section

**Mothers with vaginal deliveries who had never exposed to $\mathrm{C}$-section

\subsection{Risk Ratio of Caesarean Section}

The risk ratio (RR) for the association of $\mathrm{C}$-section deliveries with the potential predictors is displayed in Table 2. The place of residence and educational status significantly $(<$ 0.001) showed the highest differences in the risk ratios of $\mathrm{C}$-section exposure between urban and rural residents as well as $\mathrm{R} \& \mathrm{~W}$ and illiterate $(\mathrm{RR}=3.9 ; 95 \% \mathrm{C}$. I. $=2.3-6.7, \mathrm{RR}=$ $3.8 ; 95 \%$ C. I. $=2.0-7.3)$. These rates of ratios differences were followed among primip and multi-to-grand parities (RR $=2.7 ; 95 \%$ C. I. $=1.9-3.8)$ and $\leq 24$ and $>24$ maternal ages $(\mathrm{RR}=2.6 ; 95 \%$ C. I. $=1.8-3.7)$. On the other hand, marriage age $(\mathrm{RR}=1.9 ; 95 \%$ C. I. $=1.3$ - 2.8) employment status $(\mathrm{RR}=$ $1.8 ; 95 \%$ C. I. $=1.2-2.6)$, and visiting health services practice $(\mathrm{RR}=1.8 ; 95 \% \mathrm{C} . \mathrm{I} .=1.2-2.6)$ were found to be significantly associated with smaller risk ratio differences between the mothers groups in terms of their $\mathrm{C}$-section exposure.

Table 2 also shows the corresponding estimated risk ratio
(ER) for predicting $\mathrm{C}$-section deliveries among the study population. The results indicated that the risk difference in the exposure to $\mathrm{C}$-section deliveries increases about three times $(\mathrm{ER}=2.9$ and 2.8$)$ between urban and $\mathrm{R} \& \mathrm{~W}$ mothers in relative to rural and illiterate mothers, respectively. The estimated risk in the exposure increases about two times through primiparous $(\mathrm{ER}=1.7)$ and $\leq 24$ aged mothers $(\mathrm{ER}=$ 1.6). However, lower relative risks result between the women groups by their age at marriage working status and limited visiting of health center ( $\mathrm{ER}=0.7,0.8$ and 0.9 , respectively).

Table 2. Risk ratio difference in the C-section exposure among the study participants in the central area of western highlands of Yemen $(n=400)$.

\begin{tabular}{lllll}
\hline Variables & RR & $\mathbf{9 5 \%}$ C. I. & ER & $\boldsymbol{P}$ \\
\hline $\begin{array}{l}\text { Age } \\
\leq 24 \text { years }\end{array}$ & 2.6 & $1.8-3.7$ & 1.6 & $<0.001$ \\
$\begin{array}{l}\text { 24 years } \\
\text { Place of residence }\end{array}$ & 1 & & & \\
Urban \\
Rural \\
$\begin{array}{l}\text { Educational status } \\
\text { R\&W }\end{array}$ & 3.9 & $2.3-6.7$ & 2.9 & $<0.001$ \\
$\begin{array}{l}\text { Illiterate } \\
\text { Employment status }\end{array}$ & 1 & & & \\
$\begin{array}{l}\text { Employed } \\
\text { Unemployed }\end{array}$ & 1.8 & $2.0-7.3$ & 2.8 & $<0.001$ \\
$\begin{array}{l}\text { Age at marriage } \\
\leq 19 \text { years }\end{array}$ & 1 & & & \\
\hline $\begin{array}{l}\text { 19 years } \\
\text { Parity }\end{array}$ & 1.9 & $1.2-2.6$ & 0.8 & $<0.01$ \\
$\begin{array}{l}\text { Primip } \\
\text { Multi-to-grand } \\
\text { Visiting health services }\end{array}$ & 1 & $1.3-2.8$ & 0.9 & $<0.01$ \\
$\begin{array}{l}\text { Limited } \\
\text { Regular }\end{array}$ & 1.7 & $1.1-2.5$ & 0.7 & $<0.05$ \\
\hline
\end{tabular}

$\mathrm{RR}$ : risk ratio

CI: confidence interval

ER: estimated risk ratio

P: level of significance

\section{Discussion}

The present study reveals important obstetric data regarding the prevalence and predictors of caesarean section exposure in Yemen, which are vital in improving the mother and infants health. Some demographic variables showed higher differences in the prevalence rates of $\mathrm{C}$-section exposure between the women groups. These demographic variables were confirmed as significant predictors for increasing the risk of C-section deliveries among the study population. The present study indicated that maternal age, place of residence, educational status, and employment status as well as age at marriage, parity, and visiting health services practice as potential predictors for $\mathrm{C}$-section deliveries. The highest risk ratio differences in the exposure to $\mathrm{C}$-section were reported between the women groups in terms of their place of residence and educational status. These considerable discrepancies could trigger either an unnecessary or additionally needed C-section exposure among the study population.

The study results showed that the urban residents had higher risk of $\mathrm{C}$-section deliveries. This was in agreement with 
the previous reports in many developing countries [16-17]. Moreover, as the education of mothers increased the risk ratio of $\mathrm{C}$-section deliveries increased among the rural community [18]. In agreement with these findings, the study results revealed that the better educational status of the urban community showed a higher risk of $\mathrm{C}$-section deliveries than the rural community. In fact, the basic data of the present study found that the educational status is significantly higher among the urban community and the vast majority of the educated mothers were employees. As well, education has been supposed to increase the C-section-seeking behavior in India [17]. In Yemen, education is useful in providing autonomy to women to utilize the available health facilities.

The present study also suggested that maternal age is associated with a significant difference in the C-section exposure. Comparable results have been reported from younger maternal ages in Sudan and UAE [19-20]. Accordingly, higher incidences of $\mathrm{C}$-section were reported among teenage wives of less than 17 years old [21]. In agreement with previous studies carried out in some developing countries, the teenage wives reported with higher prevalence rate of $\mathrm{C}$-section exposure during this survey were mostly primiparous mothers [22].

Positive answers of visiting health services were obtained from almost three-quarters of the study participants. The better practice indicated by the study participants could be due to the availability of health facilities and access to their services to all mothers groups throughout the study area. World Health Organization indicated that limited access to inclusive obstetric care is associated with higher short and long term risk of C-section deliveries for woman and infant health as well as for upcoming pregnancies [23]. In harmony with these conclusions, results of the present survey showed that there were significant differences between the study participants in terms of their obstetric care seeking practice. The findings exhibited that the regular practice of visiting health services reflected a lower rate of C-section deliveries. Hence, improving the quality of the obstetric care is an important intervention that could provide C-section to mothers in need.

Health educational programs to support a better knowledge of benefits and risks of $\mathrm{C}$-section on maternal and infant mortality and morbidity can help in reducing the incidence of unnecessary C-section. Such programs are also effective in saving mothers and neonate lives in low income settings where $\mathrm{C}$-section is underused. The assessment of the risk ratio differences between the study participants based on their demographic variables is of significant benefit to ascertain the quality of the adjustments needed in the strategy for future intervention.

\section{Conclusions}

The prevalence of $\mathrm{C}$-section exposure is found to be $22 \%$ among the study population in the central area of the western highlands region of Yemen. Some maternal demographic variables are significantly associated with large differences in the risk ratio of $\mathrm{C}$-section such as place of residence and educational status. These findings are important for improving the knowledge of the community about maternal variables that would lead to higher levels of mortality and morbidity among mothers and infants in this poor country where the quality of obstetric care is low. Further research on risk factors of C-section, which include socioeconomic and obstetric variables, should be carried out to strengthen the study outcomes.

\section{Acknowledgments}

The authors would like to acknowledge the staffs of Al-Gadad Health Centre, Al-Wehdh Health Centre, Al-Homeat Hospital, Dhamar General Hospital, Maternal and Child Health Centre and Yemen Red Crescent Center for their generous support and cooperation in the collection of the study data. We also thankfully appreciate the study population for their participation in this study.

\section{References}

[1] P. Lumbiganon, M. Laopaiboon, A. M. Gulmezoglu, et al., "Method of delivery and pregnancy outcomes in Asia: the WHO global survey on maternal and perinatal health 2007-08," Lancet, vol. 375, pp. 490-499, 2010.

[2] J. Villar, G. Carroli, N. Zavaleta, et al., "Maternal and neonatal individual risks and benefits associated with caesarean delivery: multicentre prospective study," BMJ, 2007, doi: http://dx.doi.org/10.1136/bmj.39363.706956.55.

[3] L. Dosa, "Caesarean section delivery, an increasingly popular option," Bulletin of the World Health Organization, 2001, doi: http://dx.doi.org/10.1590/S0042-96862001001200022

[4] J. P. Vogel, A. P. Betrán, N. Vindevoghel, et al. "Use of the Robson classification to assess caesarean section trends in 21 countries: a secondary analysis of two WHO multicountry surveys," Lancet Global Health, vol. 3, pp. 260-270, 2015.

[5] F. Althabe, C. Sosa, J. M. Belizán, L. Gibbons, F. Jacquerioz and E. Bergel, "Cesarean section rates and maternal and neonatal mortality in low, medium, and high income countries: an ecological study," Birth, vol. 33, pp. 270-277, 2006.

[6] C. Ronsmans, S. Holtz and C. Stanton, "Socioeconomic differentials in caesarean rates in developing countries: a retrospective analysis," Lancet, vol. 368, pp. 1516-1523. 2006.

[7] J. Ye, J. Zhang, R. Mikolajczyk, M. R. Torloni, A. M. Gülmezoglu and A. P. Betrán, "Association between rates of caesarean section and maternal and neonatal mortality in the $21^{\text {st }}$ century: a worldwide population-based ecological study with longitudinal data BJOG, vol. 123, pp. 745-753, 2016.

[8] Appropriate technology for birth," Lancet, vol. 326, pp. 436437, 1985, doi: 10.1016/S0140-6736 (85) 92750-3.

[9] World Health Organization (WHO). The Global Numbers and Costs of Additionally Needed and Unnecessary Caesarean Sections Performed per Year: Overuse as a Barrier to Universal Coverage. Geneva, Switzerland: WHO, 2010.

[10] F. El-Zanaty, and W. Ann, "Egypt Demographic and Health Survey 2008," Cairo, Egypt: Ministry of Health, 2009. 
[11] A. P. Betrán, M. Merialdi, J. A. Lauer, W. Bing-Shun, J. Thomas, P. L. Van and M. Wagner, "Rates of caesarean section: analysis of global, regional and national estimates," Paediatric and Perinatal Epidemiology, vol. 21, pp. 98-113, 2007.

[12] World Health Organization (WHO). The world health report 2005, Basic Indicators. Geneva, Switzerland: WHO, 2005.

[13] Directorate General of Planning [Oman]. Annual Health Report 2009, Sultanate of Oman: Ministry of Health, 2010

[14] Central Statistical Organization (CSO) [Yemen] and Macro International Inc. (MI), Yemen Demographic and Maternal and Child Health Survey 1997. Calverton, Maryland: CSO and MI, 1998.

[15] A. A. Al-Rukeimi, A. Al-Haddad and I. Adam, "Overuse of cesarean delivery at Al-Saudi Hospital, Hajjah, Yemen," Sudan Journal of Medical Sciences, vol. 8, pp. 185-188, 2013.

[16] K. N. Ondimu, "Levels and risk factors of operative deliveries in four health facilities in Kisumu District, Kenya," Journal of Obstetrics \& Gynecology, vol. 20, pp. 486-491, 2000.

[17] S. S. Padmadas, S. Kumar, S. B. Nair and A. Kumari, "Caesarean section delivery in Kerala, India: evidence from a National Family Health Survey," Social Science and Medicine, vol. 51, pp. 511-521, 2000.
[18] S. Tang, X. Li and Z. Wu, "Rising cesarean delivery rate in primiparous women in urban China: Evidence from three nationwide household health surveys," Am. J. Obstet. Gynecol., vol. 195, pp. 1527-1532, 2006.

[19] Ministry of Public Health [Sudan]. Sudan Maternal and Child Health Survey: Principal Report. Republic of Sudan and the Pan Arab Project for Child Development (PAPCHILD) of the League of Arab States, 1995.

[20] A. S. Kumari, "Pregnancy outcome in women with morbid obesity," International Journal of Gynecology \& Obstetric, vol. 73, pp. 101-107, 2001.

[21] P. M. Tebeu, E. Mboudou, G. Halle, E. Kongnyuy, E. Nkwabong, and J. N. "Fomulu, Risk Factors of Delivery by Caesarean Section in Cameroon (2003-2004): A Regional Hospital Report," ISRN Obstetrics and Gynecology, vol. 2011, Article ID 791319, 2011

[22] P. M. Tebeu, L. Kouam, M. F. Nghonguia et al., "Historical cohort study of delivery in woman at forty years and above," Revue Medicale de Liege, vol. 62, pp. 509-514, 2007.

[23] World Health Organization (WHO). WHO Statement on Caesarean Section Rates. Geneva, Switzerland: WHO, 2015. 